\title{
María Candelaria Valdés Silva (2016), Ateneo Fuente: Ia forja de un patrimonio escolar, Fontamara/Universidad Autónoma de Coahuila, México
}

\author{
Salvador Camacho Sandoval \\ Universidad Autónoma de Aguascalientes \\ camacho_sal@yahoo.com.mx
}

Con pasión y rigor académico, María Candelaria Valdés Silva escribió este libro sobre una institución muy importante para México, especialmente para el norte del país y para la historia de Coahuila. Por ello no es casual que la autora deje sus recatos a un lado y afirme: "Su memoria es nuestra memoria. Su historia es nuestra historia". Al leer el libro, se comprenden estas palabras y, ciertamente, su relevancia se impone. Se trata de un libro que busca en una institución educativa conocer el pulso de una historia social. En este sentido, la investigación es una aportación relevante a la historiografía de la educación en México y en América Latina, por lo cual ya participa en un fructífero diálogo con otros estudios sobre el particular, o semejantes temas socioeducativos.

La consulta de fuentes primarias es extensa y rigurosa, además de que para la elaboración de este libro la autora se apoyó en herramientas teóricas de la sociología y la historia. Esta fundamentación fue útil y sirvió de brújula para dar sentido a la información que se encontró en cientos de documentos oficiales, folletos institucionales, cartas y oficios de directivos y maestros, peticiones de alumnos y padres de familia; además de las fuentes secundarias (libros y artículos relativos a los temas estudiados). Valdés Silva nos dice que la historia del Ateneo pasó por tres grandes periodos, entre 1867, año de creación, y 1910, año en que ella decidió terminar su búsqueda.

Para comprender el origen y desarrollo del Ateneo, la autora retrocede en el tiempo y analiza los proyectos educativos y culturales del México independiente, alimentados con ideas ilustradas provenientes de Europa, y habían calado en ciertos grupos políticos y círculos de intelectuales en el virreinato. Por ello, en las primeras décadas del siglo XIX, en el estado de Coahuila y Texas, se dio importancia a la propagación de las "luces", a través del mundo de las escuelas (como las lancasterianas) y otras instituciones culturales y políticas. 
Llama la atención cómo el estado estaba adelantado a su tiempo, en comparación con otras entidades del país, al impulsar lo que ciertos investigadores llaman "modernización y secularización de la sociedad", a través de una creciente separación de los asuntos de la Iglesia católica y del Estado, así como de la generación de nuevas actividades económicas. Por eso, cuando se creó el Ateneo, décadas después, ya existía una tradición que influyó para que el proyecto educativo estuviera apegado a los lineamientos del liberalismo y de la nueva república.

El camino no fue fácil, pues, aún a mediados del siglo, varias instituciones confesionales seguían ocupando los lugares que le correspondían a las instituciones laicas. Además, la situación de Coahuila y de todo México era de inestabilidad, y los jóvenes carecían de oportunidades para el estudio y el trabajo. Bien lo dijo un gobernador de aquella época: "¿cómo esperar ilustración y virtudes en la postrera juventud, cuando la vemos con dolor en el ocio y abandono?". Muestra de este panorama hostil e incierto era la separación de Texas, la lucha interna entre liberales y conservadores, las incursiones de indígenas que seguían disputando su territorio, la unión de Coahuila con Nuevo León, la falta de comunicación en un territorio grande con poca población, los gobiernos débiles y con problemas económicos y prioridades militares.

De allí la importancia de una institución educativa como el Ateneo Fuente, que de inmediato se convirtió en un referente cultural y social, no sólo del estado, sino también de la región, pues muchos de los jóvenes llegaron de entidades aledañas. Según nos cuenta Valdés Silva, entre 1867 y 1910, 43 años de vida analizados, hubo 4,955 alumnos inscritos, quienes tuvieron un gran apego a la institución, tal como lo tuvo Vito Alessio Robles, quien escribió en sus memorias: "Ingresé al Ateneo Fuente, escuela preparatoria del estado de Coahuila, por la que todos los hijos de esta entidad federativa hemos tenido y conservamos gran cariño".

La autora hizo un trabajo titánico de búsqueda y recopilación de información (una labor de hormiga) y elaboró una gran "biografía colectiva" sin precedente, de tal suerte que ahora sabemos mucho del perfil escolar y familiar de los estudiantes en el periodo que ella investigó. En ese periodo, por ejemplo, el 87.5 por ciento de los alumnos era de Coahuila, y el 12.5 por ciento de otras entidades, incluso de otros países, como Estados Unidos, Italia y hasta de Arabia (Valdés Silva señala con precisión el porcentaje de alumnos de estos lugares: de las entidades, señala que de Nuevo León procedía el 4.4 por ciento de estudiantes, de San Luis Potosí el 1.25 por ciento). También descubrió que, de los 36 municipios de entonces, el 48 por ciento de alumnos era de Saltillo y el 52 por ciento de otros municipios: Ramos Arizpe (5.4\%), Monclova (4\%), Arteaga (3\%).

Ahora sabemos que en esa escuela había alumnos que ingresaban muy pequeños, quizás frisaban los 13 años, que convivían con estudiantes de licenciatura, algunos de los cuales tenían ya 30 años. Sabemos también cuántos estaban internados y cuántos no pagaban mensualidad; además, podemos conocer que, debido a decisiones gubernamentales, hubo cambios que trastocaron la dinámica y el perfil del Ateneo. Por ejemplo, en el primer periodo 
que estudia Valdés Silva (de 1867 a 1880) sólo hubo estudios de preparatoria (1,114 alumnos) y de jurisprudencia (204); en el segundo periodo (entre 1881 y 1893) se agregaron a estos estudios las carreras de Medicina, Farmacia, Escribano/Notario público, Teneduría de libros y Telegrafía; pero en el tercer periodo (entre 1894 y 1910) se restringieron las opciones y sólo se tuvo preparatoria, jurisprudencia y telegrafía, aunque se agregó Comercio, con un buen número de alumnos (324).

Analizando los cuadros que el libro presenta en el apartado de anexos, nos percatamos de que, si bien hubo un número significativo de alumnos inscritos, también era verdad que el índice de abandono escolar no era menor. Por ejemplo, en la carrera de Medicina, entre 1881 y 1893, en primer grado había 21 estudiantes inscritos, pero en el quinto sólo había 4; en estudios de Notario o escribano público, en primer grado hubo 11 alumnos, y en cuarto grado sólo 2; mientras que, en jurisprudencia, en primer grado estaban inscritos 54 y en sexto 13.

El libro tiene varios acercamientos a la vida del Ateneo, pues así como trata sus vínculos con su entorno sociopolítico y económico, también analiza lo que ocurría dentro de la institución, aunque la autora acepta, con razón, que conocer lo que sucedía en el Ateneo no es fácil. Aun así, logró dar cuenta de la vida estudiantil: exámenes, premiaciones, atribuciones y perfiles de los maestros, entre otros. Por ejemplo, de las actividades estudiantiles fuera de la escuela, Valdés Silva, con un tono fresco y ameno, reconstruye momentos relevantes de los estudiantes e interpreta muy bien lo que significó para los jóvenes de comunidades rurales radicar en Saltillo y cursar en el Ateneo: había "asombro — nos dice la autora- de conocer escenarios distintos a los acostumbrados en el medio árido y bárbaro" de donde provenían esos muchachos.

Obviamente, para muchos jóvenes, sus inicios en la vida amorosa tenían lugar en el Ateneo y sus tiempos de recreación eran generalmente grupales, por lo cual los alumnos hacían veladas literarias, se reunían para jugar naipes, ajedrez o pelota, y se organizaban en grupos para llevar "gallo" a las muchachas del lugar, e ir a las fiestas y serenatas que se hacían en la Plaza Independencia, en la de San Francisco y en la Alameda.

Con esmero, en el libro se cuenta de esa suerte de arrojo de los ateneístas, quienes, en jardines y plazuelas, espiaban furtivamente la salida de las jóvenes de los establecimientos escolares para señoritas que se hallaban cerca del instituto: "Ahí tenían oportunidad, aunque fuese de lejos, de reconocerse en miradas mutuas, anticipo de la posibilidad del noviazgo y, a futuro, por qué no, la formalización de la pareja”, cuenta la autora.

En suma, con esta referencia elocuente del mundo juvenil en el Ateneo, el libro es una historia con muchas vertientes de carácter escolar y cultural, además de social y político. Su presencia es clave y tiene ya un lugar en el imaginario colectivo de los coahuilenses. Ciertamente, como señala el epígrafe del libro (en que se cita a George Steiner): "donde existe un vacío, surgen nuevas energías y realidades que sustituyen a las antiguas". Así ocurrió con el 
Ateneo Fuente en la historia de Saltillo, y también así ocurre con este libro que surgió ante ciertos vacíos historiográficos. María Candelaria Valdés Silva contribuye a reiterar que México es un mosaico y que esto se expresa en su educación, por lo que hacer historia de una institución en un espacio geográfico específico permite encontrar la riqueza de la diversidad en el país. De este tipo de aportaciones, al hacer una reflexión sobre la historiografía de la educación en México, Anne Staples ha dicho:

Los trabajos más recientes permiten constatar la especialización en este campo del conocimiento y, sobre todo, de las etapas y lugares que, por falta de documentos o de investigadores, permanecían en la oscuridad. Se va conociendo más a México en toda su variedad, sabores, texturas y demás características [...]. México es un mosaico de idiomas, etnias, costumbres y mentalidades, y la educación, obviamente, refleja y reproduce ese mosaico. Por mucho que se haya tratado de centralizar la educación para que fuera un medio para homogeneizar a la población y darle un sentimiento de nacionalismo unificador, y por mucho que los medios actuales de comunicación lo hayan facilitado, no cabe duda que estamos lejos de este ideal, que en sí es cuestionable (Staples, 2018: 65-66).

Un día, María Candelaria Valdés Silva llegó con sus maestros del doctorado y les dijo que investigaría la historia del Ateneo Fuente. Así lo hizo durante varios años y trabajó con constancia y rigurosidad profesional, a lo que ella agregó el rasgo ameno y claro para beneficio de sus lectores. Con su investigación se reivindica un patrimonio intangible de gran valor para Coahuila y para todo el país. Y, como decimos los historiadores, con este rescate de un pasado glorioso es como afianzamos identidades y construimos un futuro más generoso para las nuevas generaciones.

\section{Referencias}

Staples, Anne (2018), "Apuntes sobre la nueva historiografía educativa”, en Salvador Camacho Sandoval, coord., La lechuza extraviada. Desencuentros: reformas educativas y magisterio, Universidad Autónoma de Aguascalientes, México, pp. 65-81. 